\title{
MYCOTIC ANEURYSM OF THE ABDOMINAL AORTA
}

\author{
BY \\ R. G. MITCHELL and A. E. CLAIREAUX \\ From the Roval Hospital for Sick Children, Edinburgh and the Department of Pathology, University \\ of Edinburgh
}

(RECEIVED FOR PUBLICATION AUGUST 9, 1951)

Mycotic aneurysms occurring during the course of bacterial endocarditis have hitherto been largely of academic interest owing to the fatal nature of the primary condition, but with recent advances in the treatment of endocarditis such complications are becoming of greater importance, particularly as they may themselves be a cause of death. Haemorrhage from rupture of a mycotic aneurysm was the main cause of death in 17 of the 408 cases of subacute bacterial endocarditis treated with penicillin in the Medical Research Council series (Cates and Christie, 1951), and in two cases a peripheral aneurysm developed after the end of treatment.

Mycotic aneurysms seldom develop in the abdominal aorta and there are few reports of such a complication of bacterial endocarditis. We recently observed the following case of pneumococcal endocarditis in a child, whose death was caused by rupture of a mycotic aneurysm of the abdominal aorta.

\section{Case Report}

A girl of 10 years and 11 months was admitted to the Royal Hospital for Sick Children, Edinburgh, on May 4, 1951.

The child was well until three weeks before admission when she came home from school feeling cold and sìivery. That evening she became flushed and feverish and was in bed for two days, after which she felt better. However, the symptoms recurred within a day of getting up and she had to return to bed. From that time until admission she was listless and ill, with intermittent fever and occasional vomiting. Constipation was troublesome. She did not complain of pain and had no cough. She was treated with a sulphonamide drug without much effect. A few days before admission she had an epistaxis lasting about 10 minutes.

She was born at full term by spontaneous delivery after a normal pregnancy, and her early development was satisfactory. Past illnesses included measles at 2 years, pertussis at 5 years, and varicella at 7 years.
She had several attacks of bronchitis between 1 and 5 years but none thereafter.

The family doctor stated that she had never had a heart murmur previously and had no history of rheumatism.

Her parents were healthy and she had two sisters, aged 7 and 12 years, who were both well. There was no family history of rheumatism. Social conditions were good.

On admission she was seen to be a well developed and well nourished girl, rather flushed. The temperature was $100^{\circ}$, pulse rate 150 per minute and respiration rate 32 per minute. The skin was healthy with no rash or petechiae. There was no clubbing of the fingers.

The pulse was regular in time and force: blood pressure 125 65. The apex beat was palpable in the fifth left interspace just outside the midclavicular line. A loud systolic murmur was heard, maximal at the apex but audible over the whole praecordium.

The tongue was dry and furred. There was no abdominal tenderness or rigidity and no abnormal mass was palpable. The spleen could not be felt. There were no enlarged lymph nodes.

No abnormality was found in the respiratory or nervous systems. The optic fundi were normal and remained so throughout her illness.

Investigations. A blood count gave $\mathrm{Hb} .13 \cdot 7 \mathrm{~g} .{ }^{\circ}$, leucocytes 16,400 per c.mm. (polymorphs $84 \%$, lymphocytes $14 \%$, monocytes $2 \%$ ). The blood sedimentation rate was $22 \mathrm{~mm}$. in one hour (modified Cutler micromethod). The urine had a specific gravity of 1020 . No albumin or sugar was found, but a few red and white cells were seen microscopically.

The Mantoux test $(1,1000)$ was negative, as also was the Paul Bunnell test. There was no agglutination with B. typhosus, B. paratyphosus A and B, Salmonella, or Brucella abortus.

Progress. On the day after admission her temperature rose to $104^{\prime}$; it fell next morning and rose again to $101 \cdot 4^{\text {: }}$ on the following day. Blood was taken for culture on two occasions when the temperature was rising, and both specimens grew a pneumococcus, of the same sensitivity to penicillin as the standard Oxford staphylococcus. 
A tentative diagnosis of bacterial endocarditis was made and treatment with penicillin, 500,000 units intramuscularly every four hours, was started on the third day after admission. On the fourth day she suddenly developed complete hemiplegia on the left side and had signs of slight meningeal irritation. A lumbar puncture showed clear cerebrospinal fluid, with 49 cells per c.mm., mainly lymphocytes, and protein $30 \mathrm{mg} . \%$, sugar $55 \mathrm{mg} . \%$ and chlorides $700 \mathrm{mg} . \%$. A search was made for further embolic signs and a small, acutely tender, purple swelling was found in the pulp of the right fifth finger.

An electrocardiogram taken five days after admission showed a rate of 115 minute, a normal rhythm, no axis deviation and PR interval $0 \cdot 14$ seconds. The unipolar extremity leads and precordial leads were normal.

One week after admission she complained of pain in the left hypochondrium and tenderness was elicited on deep palpation in that region, but the spleen could not be felt. During the next few days, her temperature gradually fell and the hemiplegia improved. No change was noted in the heart murmur and no more embolic signs were found. In view of this improvement, no further lumbar puncture was carried out.

Her general condition remained good and she became much brighter. However, three weeks after admission her temperature rose to $102^{\circ} \mathrm{F}$. and she complained of pain in the left shoulder. A radiograph of the chest taken in the ward showed no pulmonary lesion and no enlargement of the heart. The white blood cell count was 17,200 per c.mm., and further blood specimens were sterile on culture.

Thereafter she again improved and her temperature fell to normal for nine days, during which she was rather apathetic, although her general condition was remarkably good. She occasionally complained of pain in the limbs, especially in the left hip, abduction of which was painful. No abnormality of this joint was visible radiologically.

At the end of the apyrexial period the following results were obtained: Hb. $13 \cdot 7$ g. $\%$ : leucocytes 16,600 per c.mm. A chest radiograph showed no pulmonary lesion, and an electrocardiogram was normal. Blood pressure was 140100 . The urine was normal, with $11 \mathrm{mg} . \%$ blood urea nitrogen. Serum albumin was $4.95 \mathrm{~g} . \%$ and serum globulin $3.7 \mathrm{g.} \%$.

Five weeks after admission, her temperature again rose and she lost her appetite. Next day she complained of mid-abdominal pain: no abnormality was found on examination of the abdomen. The pain continued however, and two days later a firm, tender, pulsatile swelling was just palpable below the umbilicus. This swelling increased slowly in size and a systolic bruit transmitted down the femoral arteries was audible. $A$ tentative diagnosis of aneurysm of the abdominal aorta was made and streptomycin was started in addition to the penicillin. It was decided that laparotomy, with surgical treatment of the aneurysm if possible, offered the only hope of recovery, but before this could be carried out she suddenly complained of severe abdominal pain and a swelling appeared in the left side of her abdomen.
Blood transfusion was immediately started, but she rapidly became extremely pale and weak and died within half an hour.

\section{Necropsy Report}

Necropsy was carried out on June 13, 1951. The body was that of a well developed female child aged 11 years. No congenital abnormality was found on external examination.

Head. The dura mater and leptomeninges were healthy. The brain was firm, but on section there was a large area of softening in the right cerebral hemisphere which had partially destroyed the basal ganglia and the wall of the right lateral ventricle (Fig. 1). The softened area measured $6 \mathrm{~cm}$. by $3 \mathrm{~cm}$. by $2 \mathrm{~cm}$. and showed pronounced yellow discoloration. The appearance was that of a large infarct resulting from embolism of the right middle cerebral artery or one of its large branches. Dissection of the right middle cerebral artery and of its major branches failed to demonstrate an aneurysm. The left cerebral hemisphere was normal. The mid-brain, pons, cerebellum and medulla oblongata were healthy.

Thorax. The pharynx and oesophagus, trachea, bronchi and lungs were healthy. The pericardium was clear and glistening. There was no free fluid in the pericardial sac. The heart was moderately enlarged, chiefly as a result of dilatation of the right ventricle. The myocardium of the right ventricle was flabby. The right atrium was normal and the tricuspid valve admitted three fingers. The pulmonary valve was healthy. The myocardium of the left ventricle was of normal thickness and rather pale. The aortic valve was healthy. The mitral valve showed an area of ulceration $0.5 \mathrm{~cm}$. in diameter extending upwards from the valve ring. There were two groups of pale vegetations over the posterior cusp. The endocardium of the left atrium was healthy. The coronary arteries and great vessels had a normal appearance.

Abdomen. A very large quantity of clotted blood was lying extraperitoneally in the anterior and lateral abdominal walls. The peritoneum was clear and glistening with no free fluid in the peritoneal sac. The stomach and intestines were healthy. The liver was slightly enlarged and the cut surface was pale. The spleen was twice the normal size. The capsule was thickened over the lower pole and a large infarct, $4.5 \mathrm{~cm}$. by $2 \mathrm{~cm}$. by $1.5 \mathrm{~cm}$., was present in this situation (Fig. 2). The infarct was clearly demarcated from the surrounding splenic pulp and was bright yellow. The splenic pulp was pale and soft. The pancreas and suprarenal glands were healthy. The left kidney was 
FrG. 1.-Section of brain showing destruction in the right cerebral hemisphere.
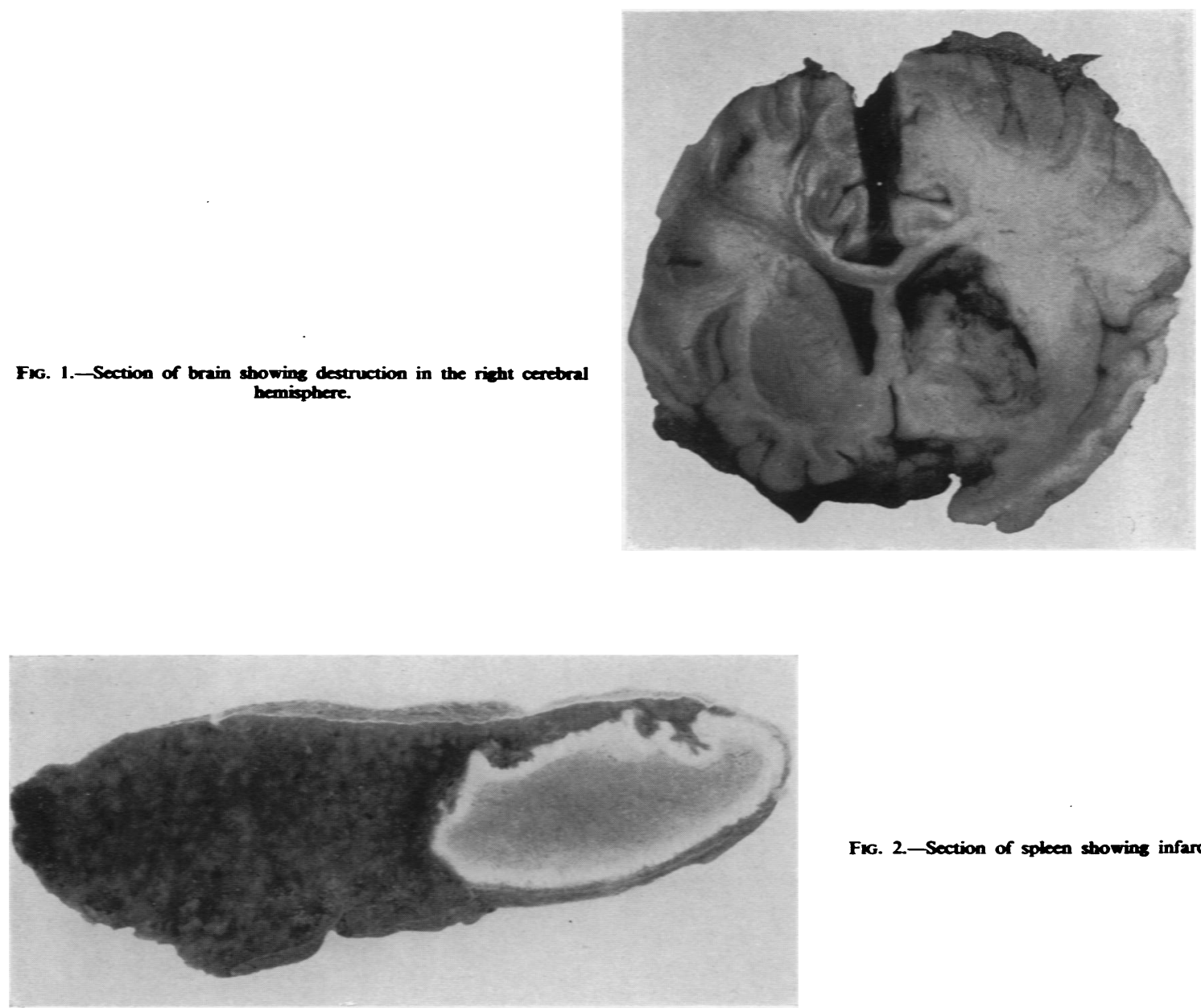

FiG. 2. Section of spleen showing infarct.

Fig. 3.-Abdominal aorta opened posterionty to display the ancurysm.

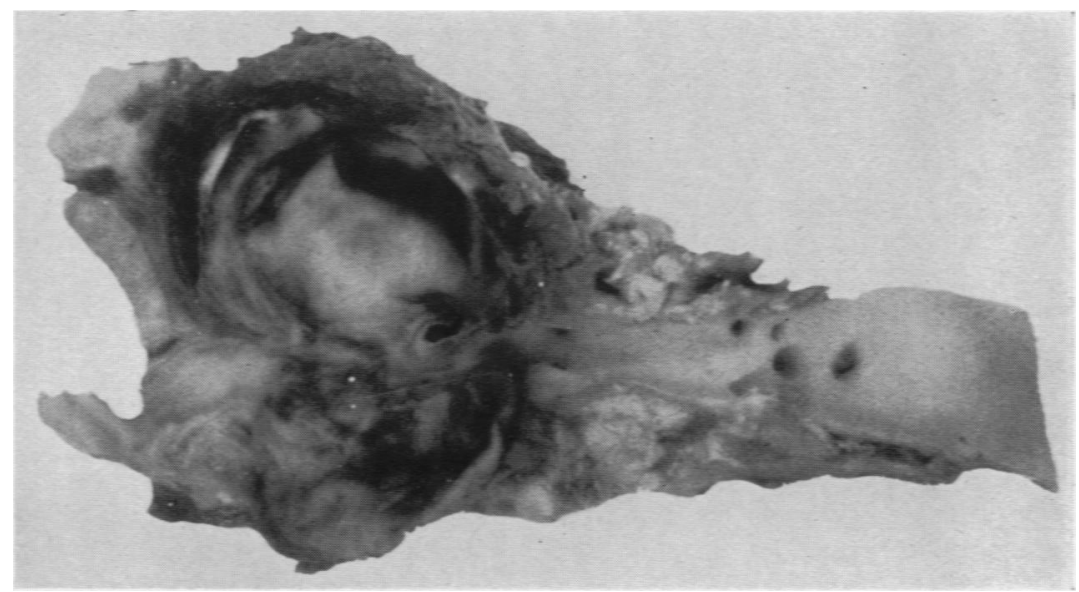

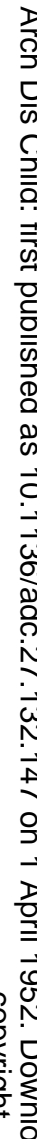

음 을

ำ

일

을

官

बิ

응

고.

옥

잉

을.

ก

N

N

맘

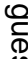

$+$

To

움 
surrounded by a mass of retroperitoneal blood clot. Both kidneys were structurally normal. The ureters, bladder, ovaries and uterus were healthy.

The abdominal aorta was then examined and a large aneurysmal dilatation, $7 \cdot 5 \mathrm{~cm}$. by $4 \mathrm{~cm}$. by $4 \mathrm{~cm}$., was found arising from the posterior aspect of the aorta $1.5 \mathrm{~cm}$. above the bifurcation. The wall of the aneurysm was composed largely of fibrin and laminated blood clot. Only a narrow central band of aortic wall remained (Fig. 3). The dilatation was thus a false sac which had been formed by slow leakage from a mycotic aneurysm of the lower abdominal aorta and had eventually ruptured, causing a fatal retroperitoneal haemorrhage. A mural thrombus was also present in the left common iliac artery and the left external iliac artery was completely occluded by thrombus. The right common iliac artery and its branches were clear.

Bacteriological Report. A direct film made from one of the vegetations on the mitral valve showed a few polymorphonuclear leucocytes, lymphocytes and Gram-positive cocci. Only post-mortem contaminants were obtained on culture. The brain lesion was sterile.

Histological Report. The myocardium was healthy and the interstitial tissue had a normal appearance. There was no evidence of previous rheumatism. The vegetations from the mitral valve were found to consist of organizing platelet thrombi with infiltration of the valve cusp by polymorphonuclear leucocytes and lymphocytes. No organisms were found. The valvular endothelium had been destroyed and the appearance was that of healing ulcerative endocarditis.

Sections from the wall of the aneurysm in the aorta confirmed that it was composed of fibrin clot. Masses of polymorphonuclear leucocytes were enmeshed in the fibrin network.

A large infarct with a well defined margin was present in the spleen. The infarcted area showed complete loss of structure. The surrounding pulp contained numerous polymorphonuclear leucocytes. The Malpighian bodies appeared normal.

The infarcted area of the brain showed complete loss of nerve cells and ground substance. At the margin of the infarct a reparative gliosis was taking place.

The liver, kidneys and pancreas showed no abnormality.

The findings may be summarized as acute endocarditis, aneurysm of the abdominal aorta, infarction of brain and spleen, terminal retroperitoneal haemorrhage.

\section{Discussion}

Bacterial infection may invade a vessel wall from without or from within, so that mycotic aneurysms may be of extravascular or intravascular origin. Bacterial endocarditis is much the most common cause of the latter group, having been present in 187 of 217 collected cases of mycotic aneurysm of intravascular origin (Stengel and Wolferth, 1923).

Subacute bacterial endocarditis is not common in children and malignant endocarditis is equally rare. Schlesinger (1928) found only 10 cases of acute malignant endocarditis in 67 years in the records of The Hospital for Sick Children, Great Ormond Street. Pneumococcal endocarditis is particularly unusual in childhood as it occurs in an older age group than endocarditis due to other organisms. Thayer (1931) found that only $4 \cdot 76^{\circ} \%$ of his 306 cases occurred in the first two decades. The disease usually has a rapidly fatal course, although Blumer (1923) reported 16 patients who survived for more than three months.

The portal of entry of the pneumococcus is usually known (Thayer, 1931) but in the present case no primary focus of infection could be discovered. In one-third of a series of 23 cases, however, Lord (1932) was uncertain of the source of the infection. The pneumococcus usually attacks a healthy valve, as in this case, and in the majority of instances the lesions are confined to the left side of the heart.

Although aneurysms of the heart valves and root of the aorta due to direct ulceration are relatively common, mycotic aneurysms of embolic origin occur infrequently. Thayer (1926) found no embolic aneurysms in 60 necropsies on cases of bacterial endocarditis and Blumer (1923) found only nine in 150 collected necropsies, two of these being in the aorta.

Aneurysm of the Abdominal Aorta. Saccular aneurysms of the abdominal aorta are not uncommon in adults but are seldom encountered in children. Only three of Nixon`s 233 patients were under 20 years of age (Nixon, 1911). These aneurysms are usually caused by syphilis or arteriosclerosis (Epstein, 1945) and bacterial infection is rare, but it assumes greater relative importance in childhood when syphilis and arteriosclerosis are infrequent (Bronson and Sutherland, 1918). Kampmeier (1936) collected 381 cases of aneurysm of the abdominal aorta but did not mention bacterial infection in discussing the aetiology. In a series of 96 cases of abdominal aneurysm, Scott (1944) found that in 68 the aorta was involved. Eighteen of his whole series were cases of mycotic aneurysm but in only three of 
these was the aorta involved. Thirteen of the 18 patients had bacterial endocarditis but it was not stated whether these included the three cases of aortic aneurysm. Stengel and Wolferth (1923) found 66 cases of mycotic aortic aneurysm, but in 60 of these the root or arch of the aorta was involved and it was not stated whether any of the remaining six were abdominal.

No mycotic aneurysms were found by Hubeny and Pollack (1940) in 48 cases of saccular aneurysm of the abdominal aorta, nor by Garland (1932) in 16 cases. Rottino (1943) reported that four of his 31 cases were mycotic but none was due to endocarditis. In the series of 596 cases of aneurysm reviewed by Mills and Horton (1938) in 26 the abdominal aorta was involved, but none was due to endocarditis.

Mycotic aneurysms of the abdominal aorta may be caused by weakening of the vessel wall by contiguous disease as in Preioni's case referred to by Revell (1945), which was due to a pneumococcal abscess, but those arising in the course of bacterial endocarditis are considered to be due to small infected emboli from the valves which lodge in the vasa vasorum of the aortic wall (Eppinger, 1887; Chamberlain, 1943). A similar pathogenesis may be invoked for primary mycotic aneurysms, such as those described by Revell (1945), which occur during the course of pyogenic infection elsewhere in the body. These are presumably due to bacterial embolism of the vasa vasorum, as it is unlikely that bacteria could cause endarteritis of the intact intima of the abdominal aorta.

Rarely, tuberculosis may be the cause, either by spread of the tuberculous process to the aortic wall from neighbouring lymph nodes (Dafoe, 1925) or possibly by bacterial embolism as in the case described by Jacobi (1890), in which a girl of 5 with a tuberculous hip developed an aneurysm of the abdominal aorta.

It is possible that congenital deficiency of elastic tissue in the aortic wall could result in an aneurysm, and Gibson (1946) reported such a case in a boy of 16 months, who died after rupture of an aneurysm of the abdominal aorta for which no cause was found. However, the congenital nature of the lesion was not proved and it could equally well have been a primary mycotic aneurysm.

A search of the literature has revealed only five reported cases of mycotic aneurysm of the abdominal aorta caused by bacterial endocarditis. All occurred in childhood.

CASE 1 (ATTKen, 1898). A boy of 9 years, with a past history of rheumatism, who died of heart disease. Necropsy revealed vegetations on the aortic valve, with perforation of one of the cusps. There was an aneurysm the size of a golf ball on the anterior aspect of the abdominal aorta at its bifurcation.

CASE 2 (AleXejew, 1898). A girl of 10 years, who had pain and depression for eight weeks. There was palpable pulsation under the umbilicus, and the pulse in the left crural artery was smaller than that on the right. Necropsy revealed vegetations on the mitral valve and an aneurysm of the abdominal aorta.

CASE 3 (Baginsky, 1908). A boy of 7 years and 9 months, with no history of rheumatism, was admitted with pain in the extremities. He developed a pulsating mass in the mid-abdomen, and necropsy revealed a large aneurysm of the abdominal aorta, and another the size of a walnut on the subclavian artery. There were vegetations on the mitral valve and infarcts in the spleen and kidney.

CASE 4 (Nixon, 1911). A boy of 14 years died of infective endocarditis, and had an aneurysm the size of a pigeon's egg on the abdominal aorta at the bifurcation.

Case 5 (Rost AND Fischer, 1928). A child of $11 \frac{1}{2}$ years, who had subacute bacterial endocarditis, developed an aneurysm of the abdominal aorta. No necropsy was allowed.

The first four cases can be accepted, but in the case of Rost and Fischer the diagnosis was not verified by post-mortem examination, and therefore the aneurysm may have been on a smaller vessel such as the superior mesenteric artery, a commoner site than the abdominal aorta. The three cases reported by Scott (1944) have not been included because no clinical details were given, and it was not stated that they were due to bacterial endocarditis.

With an increasing proportion of recoveries from bacterial endocarditis, such cases may be encountered more frequently, as no doubt many cases in the past have been missed, or considered of no importance because of the serious nature of the primary illness, and therefore not reported. Since the behaviour of mycotic aneurysms under medical treatment is unpredictable (Cates and Christie, 1951), it is important that a careful watch should be kept for such complications, which may have to be dealt with surgically, especially when they are so situated as to endanger the patient's life.

\section{Summary}

Mycotic aneurysm of the abdominal aorta is an uncommon but serious complication of bacterial endocarditis.

The case of a child who died after rupture of such an aneurysm is reported, with details of the necropsy.

Five further cases, all occurring in childhood, have been collected from the literature.

The condition is briefly reviewed.

We are grateful to Dr. D. N. Nicholson for permission to report this case. 


\section{REFERENCES}

Aitken, R. Y. (1898). Brit. med. J., 1, 1655.

Alexejew, N. N. (1898). Quoted by Le Boutillier, T. (1903). Amer. J. med. Sci., 125, 778.

Baginsky, A. (1908). Berl. klin. Wschr., 45, 144.

Blumer, G. (1923). Medicine, Baltimore, 2, 105.

Bronson, E. and Sutherland, G. A. (1918). Brit. J. Child. Dis., 15, 241.

Cates, J. E. and Christie, R. V. (1951). Quart. J. Med., n.s. $20,93$.

Chamberlain, E. N. (1943). Brit. Heart J., 5, 121.

Dafoe, W. A. (1925). Edinb. Med. J., 32, 291.

Eppinger, H. (1887). Arch. klin. Chir., 35. Supplement.

Epstein, J. (1945). Ann. intern. Med., 22, 252.

Garland, H. G. (1932). J. Path. Bact., 35, 333.

Gibson, T. A. (1946). Amer. J. Dis. Child., 71, 654.
Hubeny, M. J. and Pollack, S. (1940). Amer. J. Roentgenol., 43, 385.

Jacobi, A. (1890). Arch. Pediat., 7, 161.

Kampmeier, R. H. (1936). Amer. J. med. Sci., 192, 97.

Lord, F. T. (1932). New Engl. J. Med., 207, 767.

Mills, J. H. and Horton, B. T. (1938). Arch. intern. Med., 62, 949.

Nixon, J. A. (1911). St Bart's Hosp. Rep., 47, 43.

Revell, S. T. R. (1945). Ann. intern. Med., 22, 431

Rost, W. L. and Fischer, A. E. (1928). Amer. J. Dis. Child., 36, 1144.

Rottino, A. (1943). Amer. Heart J., 25, 826.

Schlesinger, B. (1928). Brit. J. Child. Dis., 25, 33.

Scott, V. (1944). Amer. J. Syph., 28, 682.

Stengel, A. and Wolferth, C. C. (1923). Arch. intern. Med., 31, 527.

Thayer, W. S. (1926). Johns Hopk. Hosp. Rep., $22,1$. (1931). Edinb. med. J., 38, 237. 